\title{
Developing compassionate leadership in health care: an integrative review
}

This article was published in the following Dove Press journal:

Journal of Healthcare Leadership

18 December 2015

Number of times this article has been viewed

\author{
Paquita $C$ de Zulueta \\ Department of Primary Care and \\ Public Health, Imperial College \\ London, UK
}

Correspondence: Paquita $C$ de Zulueta Department of Primary Care and Public Health, Imperial College London, Charing Cross Campus, Reynolds Building, St Dunstans Road, London W6 8RP, UK Email p.dezulueta@imperial.ac.uk

\begin{abstract}
Compassionate health care is universally valued as a social and moral good to be upheld and sustained. Leadership is considered pivotal for enabling the development and preservation of compassionate health care organizations. Strategies for developing compassionate health care leadership in the complex, fast-moving world of today will require a paradigm shift from the prevalent dehumanizing model of the organization as machine to one of the organizations as a living complex adaptive system. It will also require the abandonment of individualistic, heroic models of leadership to one of shared, distributive, and adaptive leadership. "Command and control" leadership, accompanied by stifling regulation, rigid prescriptions, coercive punishments, and/or extrinsic rewards, infuses fear into the system with consequent disempowerment and disunity within the workforce, and the attrition of innovation and compassion. It must be eschewed. Instead, leadership should be developed throughout the organization with collective holistic learning strategies combined with high levels of staff support and engagement. Culture and leadership are interdependent and synergistic; their codevelopment needs to be grounded in a sophisticated, scientifically based account of human nature held within a coherent philosophical framework reflected by modern organizational and leadership theories. Developing leadership for compassionate care requires acknowledging and making provision for the difficulties and challenges of working in an anxiety-laden context. This means providing appropriate training and well-being programs, sustaining high levels of trust and mutually supportive interpersonal connections, and fostering the sharing of knowledge, skills, and workload across silos. It requires enabling people to experiment without fear of reprisal, to reflect on their work, and to view errors as opportunities for learning and improvement. Tasks and relational care need to be integrated into a coherent unity, creating space for real dialog between patients, clinicians, and managers, so that together they can cocreate ways to flourish in the context of illness and dying.
\end{abstract}

Keywords: servant leadership, compassion, complexity, adaptive, resilience, culture

\section{Introduction}

In many countries, there is a deep concern that modern health care has lost its moral compass and is struggling to provide safe, timely, and compassionate care to its citizens. Changing demographics, greater demand, rapidly evolving technology, information overflow, and financial constraints present new challenges. This is particularly evident in the UK, where recent high-profile scandals and condemnatory reports regarding health care provision have led to a great number of guidance documents, conferences, and articles on this theme. More stringent regulations, new laws, and "compassion initiatives", including the renewal of core professional values have followed. ${ }^{1-5}$ The recurrent refrain is for culture and/or leadership change. Other countries, such as the USA, also reveal problems with "compassion deficit" in health care. One survey showed 
that just over half of the patients and doctors believed that the health care system provided good compassionate care. ${ }^{6}$ The work experience of health care staff is critical to their own and their patients' well-being as well as to the overall culture of the health care workplace, emphasizing the need for the provision of staff well-being structures and practices. ${ }^{7-10}$ There is also a growing recognition of the importance and relevance of compassion to patient outcomes and, perhaps more pertinently, to the damage and suffering that ensues when it is absent or attenuated in the health care setting. The responses to these shocking and disturbing reports have also highlighted the importance of leadership in fostering or subverting compassionate health care. But can services and institutions, in the context of a fast-paced, industrialized, and marketized modern health care, reliably respond with sensitivity and compassion to patients in their care, particularly of the frail and elderly? Furthermore, health care does not exist in a vacuum - demographic, political, and sociocultural contexts influence the moral climate and, in turn, the expectations and motivations of the public and those working in health care organizations.

In this article, I set out to integrate perspectives from neuroscience, psychology, and complexity science with modern leadership and organizational theories in an endeavor to arrive at a useful synthesis. I will clarify what is meant by compassion, consider its facilitators and barriers, explore the models of leadership that are relevant and appropriate to the modern health care context, and describe an integrative realistic vision of compassionate leadership with proposals for its development. I shall also consider how changes in health care delivery - notably industrialization and marketization - in hospitals and primary care have prioritized or favored transactional care, measurable outcomes, and mechanistic solutions that have squeezed out relational care and the scope for compassionate practice.

\section{Why do we need compassion in health care?}

Organizations are described as "sites of everyday healing and pain". ${ }^{11}$ Uncontestably, health care institutions are even more so. Compassionate care involves responding with kindness and sensitivity to the vulnerability and suffering of patients (and their relatives), who may be experiencing frightening junctures in their lives, with the threat of losing their autonomy, dignity, control over their bodies, and the direction of their future lives. They may be confronting death and lack resources to cope with dying. Patients wish to have their humanity and uniqueness acknowledged. ${ }^{12,13} \mathrm{~A}$ gentle touch, mindful listening, and being truly present may be sufficient. ${ }^{14}$ The mounting evidence shows that empathy and compassion have a beneficial impact on patients' health outcomes (including mortality), enablement, and satisfaction as well as a reduction of malpractice complaints. ${ }^{15}$

\section{Compassionate health care system}

What would compassionate health care look like? In a compassionate health care system, patients and staff would feel listened to, supported, and cared for. Staff would feel empowered to show attentive kindness, to be attuned to their own needs and those of their patients, and to be free to take appropriate actions to relieve suffering. Patients would have their physical, psychological, and spiritual needs attended to. They would feel safe and their dignity restored or preserved. Care would reflect not just compassion but also competence and timeliness. There would be time to care and space to reflect and recharge. ${ }^{16}$ Compassionate leadership in turn would catalyze, foster, and sustain compassionate health care.

\section{Defining compassion}

There is considerable confusion and divergence in the conceptualization of compassion. ${ }^{17}$ But clarifying its meaning is not a mere pedantic or semantic quibbling; for if we can identify its key elements, elucidate the underlying science, and recognize the facilitators and barriers to the enactment of compassion, we can advance practical and realistic ideas for enhancing its flourishing in the health care context and set the agenda for compassionate leadership.

A recent review reveals that compassion arises out of distinct appraisal processes and has distinct behaviors, experiences, and physiological responses. ${ }^{18}$ Compassion can be defined as the altruistic concern for another person's suffering and the desire or motivate to alleviate it. ${ }^{19,20}$

Compassion refers to a deep awareness of the suffering of another coupled with the wish to relieve it [...]. Although the process of arriving at compassion can be difficult or complex, showing compassion often flows naturally $[\ldots] .^{21}$

Elsewhere I proposed that compassion is at the heart of medical ethics as it is essential for the relief of suffering, which is arguably the prime goal of medicine. ${ }^{22}$ Compassion is inherently reciprocal - it happens within and between people. It is complex and dynamic and resists quantitative measurements but is easy to recognize. Experiencing compassion makes people better able to show compassion to others, leading to a virtuous spiral. 
Compassion is often conflated with empathy (and most of the research in health care relates to empathy, not compassion), and empathy itself is multifaceted with two broad components: emotional empathy and cognitive empathy.

Emotional empathy or sympathy involves a shared experience of another person's emotional state, including joy or sadness. But empathic distress can lead to individuals focusing on themselves and on alleviating their own distress. If they lack the psychological resources to cope, they may resort to aversive responses - suppression, denial, or avoidance of the person triggering the distress..$^{23,24}$ This abandonment increases the suffering of patients yet further, as we all witness too often in the context of dying patients. ${ }^{25}$

Cognitive empathy includes the ability for perspective taking and for imagining what it is like for the other person(s) to be in the position or plight they are in - "stepping into someone else's shoes". ${ }^{26,27}$

Compassion is a broader, more vigorous concept: empathic concern is coupled with motivation to relieve the suffering of another. Cognitive empathy helps to guide an appropriate response rather than an impulsive and potentially harmful one. Importantly, compassion (unlike emotional empathy) involves distress tolerance: having the resilience to avoid being overwhelmed by afflictive emotions and thereby becoming less capable of helping. ${ }^{28}$ Indeed, one's ability to respond compassionately depends, in part, on one's self perceived self-efficacy at the time. ${ }^{29}$ The confusion between emotional empathy and compassion leads people to consider compassion as harmful, even unprofessional, and responsible for burnout. Evidence suggests, however, that cognitive empathy is protective against burnout and promotes well-being. ${ }^{30}$

\section{Science of compassion}

A functional model, based on affective neuroscience and evolutionary psychology of human emotion regulation systems, can explain why compassion is fragile in the context of competitive and/or threatening environments, such as health care institutions. In this model, there are broadly three emotion systems:

- The threat and self-protection system that helps us detect and respond to threats and harms, and is associated with emotions, such as fear, anxiety, anger, and disgust.

- The drive or resource-seeking system that drives us to seek out important resources or hedonic states, and is linked to feelings of achievement, excitement, and pleasure.
- The soothing or affiliation system that is linked to feelings of contentment, safeness, serenity, and being connected. The affiliative system develops from infancy when we experience and internalize the soothing and nurturing love of our caregivers.

These three systems should be in balance and adaptive to the situation at hand.

When we are in a threat system, we are in survival mode, the "flight, fight, or freeze system" is activated, and we are focused on self-preservation. Importantly, the threat system inhibits the affiliative system. Motives coordinate and orientate the mind/brain into "social mentalities": broadly the self-focused/competitive mentality and the other-focused/ compassionate mentality. ${ }^{31}$

Threatening and fear-laden environments stifle an individual's resourcefulness and compassion. As already highlighted, medicine is intrinsically threatening and anxiety-laden. ${ }^{32,33}$ Health care organizations are also "safety critical", such that errors can cause harm or death, generating more anxiety. ${ }^{34}$ Thus, health care professionals and their leaders need to find adaptive ways to contain anxiety and to develop and sustain self- and other-awareness and emotional resilience in order to sustain compassionate practice.

Another key finding in neuroscience research relevant to leadership development is the discovery that two largescale cortical networks can antagonize each other. ${ }^{35}$ The task-positive network (TPN) is important for nonsocial tasks, practical problem solving and decision-making, and controlling action - ie, "getting things done". In contrast, the default mode network plays a central role in emotional selfawareness, social cognition, and ethical decision-making, as well as creativity and insightful problem solving. Activity in the TPN inhibits activity in the default mode network. Hence, a highly task-orientated leader in health care will tend to be closed to new ideas or solutions, will be unaware of his own or others' emotional needs, and will be impervious to the ethical concerns of the organization. On the other hand, a highly relationship-orientated leader may have difficulties in focusing and executing the clearly defined goals. All tasks, however, have relational and analytical components, so that leadership will almost always require consideration of both. The crucial skill for leaders is to be able to toggle fluidly between the two, responding appropriately to situations as they arise. Training for this ability will be the key to compassionate and effective leadership. This will involve training in two role-specific abilities - analytical and mechanical reasoning and making social-emotional connections crucial to relationship building. Forcing people to focus almost 
exclusively on tasks, targets, and "problems" to be solved and a mechanical adherence to guidelines and algorithms will inevitably lead to TPN dominance with its attendant dehumanization.

\section{Barriers to compassion}

Compassion, albeit an innate human capability, is vulnerable to a variety of factors and can readily be eclipsed. Compassion cannot be coerced or turned on at will by some diktat or rule. Indeed, attempts to do so will result in inauthentic compassion, a forced submissiveness that is likely to lead to depression and distress in the caregiver. $^{36,37}$

A questionnaire-based study exploring the barriers to compassion distilled four distinct reliable factors that interfered with physicians' compassionate practice. ${ }^{38}$ These were

1. burnout or overload - time pressures were central to this,

2. external distractions, including bureaucratic requirements,

3. "difficult" patients and families, and

4. complex clinical situations, including uncertainty and failure of treatment.

Barriers to compassion, such as fear of death and dying, stress, depression, and burnout, have been identified in other studies. ${ }^{39}$ Bureaucratic goals can severely limit relationship-based compassionate care and lead to distress and staff attrition. This is particularly evident in the nursing research literature. ${ }^{40}$ Conflicting priorities can create emotional distress and cognitive dissonance, resulting in reduced compassion. Evidence suggests that financial incentives can reduce intrinsic motivation and "pro-social" behaviors. ${ }^{41}$ Preoccupation with financial savings and targets was identified as a key feature of the "toxic" culture in the Mid-Staffordshire scandal. If people are time pressured, too preoccupied, or distracted, they simply may not realize that people are suffering around them, as evidenced from staff reports and social psychology studies. ${ }^{42}$

\section{Facilitators for compassion: harnessing internal motivation and self-compassion}

Self-determination theory has stood the test of time and emphasizes the importance of intrinsic versus extrinsic motivation for flourishing and well-being. ${ }^{43}$ The key components of intrinsic motivation are meaning and purpose, self-directedness (autonomy), connecting with others (relatedness), and scope for mastery (competence). The majority of health professionals enter the profession with a high level of intrinsic motivation to help others and to be good at their work. Unfortunately, rigid and oppressive management, negative role models, and traumatizing experiences without the opportunity for supported reflection can extinguish the flame of compassion. But where intrinsic motivation and staff engagement are nurtured, compassionate patient-centered care can flourish. Self-compassion is a key ingredient for resilience and the sustainability of compassion, yet theories of leadership neglect this. ${ }^{4,45}$ Harnessing intrinsic motivation and self-compassion in patients may also be the key to healing and adaptation to illness.

\section{Implications for leadership}

From this account, we can deduce that leadership for compassion should involve the creation of systems that can provide a healthy containment of anxiety, support for the individuals involved, and the modeling and harnessing of positive adaptive responses to challenges. Leadership also needs to foster a culture of learning and openness, such that errors, mistakes, and hazards can be shared and discussed and new learning can evolve. A punitive regulatory approach will only make people hide their mistakes for fear of damaging their future careers or to avoid shame. Unfortunately, in the English National Health Service (NHS), the evidence attests to a culture of fear and blame with whistle-blowers put at risk of damaging repercussions if they speak up. ${ }^{46}$ As Don Berwick says: "Fear is toxic to both safety and improvement. Abandon blame as a tool and trust the goodwill and intentions of the staff". 5

\section{New leadership paradigms for compassionate health care}

A variety of conceptual frameworks for leadership have evolved over a number of years, accompanied by an abundance of definitions that fail to reach universal consensus. ${ }^{47}$ This makes selection of a coherent leadership model appropriate for compassionate health care problematic. Furthermore, the ubiquity of suffering and anxiety in health care creates an imperative for compassionate leadership but paradoxically creates conditions that make such leadership challenging and difficult to sustain. I propose that we need to abandon the classic triad of leader, followers, and influence and instead conceptualize leadership arising from the complementary theories of shared/distributed leadership, complexity science, relational approaches, and positive psychology. ${ }^{48-51}$

Defining leadership as dynamic, nonlinear, reciprocal processes and outcomes, available to everyone and not restricted to a formally designated person, signifies a renouncement of 
the theories that depict leadership as a collection of traits or characteristics residing within an individual. It also means that we abandon the heroic model of leadership and move to a model of collective or shared and distributive leadership. ${ }^{52-54}$ Leaders and followers are mutually dependent and dynamically intertwined and can be seen as the two sides of the same coin. We can democratize leadership further and use the term partners rather than followers. Personal or "soft" power can arise from colleagues' appreciation and respect and the positive attraction of values. Coercive or "hard" power works through command and control, power asymmetry, and coercion. ${ }^{55}$ Threats and punishments evoke fear, distrust, and resentment; undermine responsibility and professionalism; and shut down the affiliative system required for compassionate responses. Regrettably, reports and inquiries suggest that this form of leadership is still too prevalent in the health care context.

\section{Leadership typologies compatible with compassionate leadership}

Even if we discard an individualized trait approach to leadership, a brief outline of leadership typologies is still useful in their application for the collective. Authentic leadership includes self-awareness, internalized moral perspective, balanced processing, and relational transparency. ${ }^{56}$ Transformational leadership is associated with flourishing in organizations and has four key characteristics: idealized influence or charisma, inspirational motivation, intellectual stimulation, and individualized consideration or attention. ${ }^{57}$ But charisma has its dark side. The charismatic leader can develop hubris and dangerous narcissism, imagining that he/ she has superhuman qualities and/or use his/her power for malign or self-serving ends. ${ }^{58}$ Resonant leadership is based on the construct of emotional intelligence and specifically refers to compassion. ${ }^{59,60}$ There is a paucity of research in emotional intelligence and health care leadership, although this is growing. ${ }^{61,62}$

Servant leadership is characterized by a focus on the needs of others (altruism) and the setting aside of egoistic goals. ${ }^{63}$ Servant leadership is arguably more appropriate to the health care setting and aligned with compassionate leadership. This is particularly true in the UK, where a study of transformational leadership found that "genuine concern for others' well-being and development" was the single most important dimension and no single dimension emerged for "charisma". Also far greater themes of connectedness and inclusiveness emerged than in the USA. The authors concluded that there is a stronger sense of proximity, openness, humility, and "vulnerability" in the UK approach to leadership compared with US models. Servant leadership differs from transformational leadership (although there is a considerable overlap) in that servant leaders focus on service and people rather than on organizational goals. Furthermore, servant leaders have the belief that the organizational goals will be achieved by facilitating the growth, development, and well-being of those who work in the organization and by trusting them to undertake appropriate actions. ${ }^{64}$ Russell and Stone's model includes vision, integrity, trust, appreciation of others, and empowerment. They conclude as follows:

If countless individuals transform into servant leaders, infinitely more people would benefit. Servant leadership offers the potential to positively revolutionize interpersonal work relations and organizational life. ${ }^{65}$

Finally, adaptive leadership is needed when organizations face new challenges, and the old systems no longer work. Adaptive problems are those with no ready answers, sometimes coined as "wicked problems". These are common in health care, for example, obesity, drug abuse, violence, frailty, and so on. Leadership requires the humility to recognize that he/she does not have the answers and that followers (partners) have to share the responsibility of finding "clumsy" (imperfect) solutions, while accepting that it may well take a long time, with some trial and error. ${ }^{66}$ Leaders need to learn the art of humble inquiry, democratizing work, and listening to all the relevant voices. ${ }^{67,68}$ This implies that senior leaders should avoid becoming isolated and distant from the frontline and be prepared to engage directly with staff and patients.

\section{Urgent need for a new organizational paradigm}

In the UK and elsewhere, we regularly hear of health care organizations, such as hospital trusts, care homes, ambulance services, or specialist units experiencing severe problems requiring investigations and/or "special measures" for failures in quality and safety. The picture that emerges from these inquiries is depressingly repetitive and resonates with the findings from the Francis Inquiry: financial difficulties, understaffing, poor leadership, low staff morale, a culture of bullying, and a fear of speaking up. Something deep and tenacious is creating these "toxic" organizations. Why? And can compassionate leadership change this? Clearly, organizational change is urgently needed.

Arguably, one of the biggest barriers to compassionate care is the persistent and uncritical deployment of the theory and metaphor of the organization as a machine with 
hierarchical command and control managerial leadership. Taylor's theory of "scientific" management, ${ }^{69}$ which is over a hundred of years old, treats individuals as automated cogs carrying out rigidly prescribed activities, creating a system that is intrinsically dehumanizing, and paradoxically inefficient in the context of health care. ${ }^{70}$ Metaphors are remarkably powerful and can shape our thinking processes and our emotional responses. ${ }^{71,72}$ The machine paradigm creates the illusion of control, makes assumptions of linear causation, focuses on transactional care, and detracts from relational care. The market system also instrumentalizes people and human-to-human interactions by viewing them as monetizable and a means to an end (eg, profitability). It also attempts to slice caregiving and the experience of illness into discrete, disjointed units.

Medicine, however, is both an art and a science, involving high levels of unpredictability and emotional charge, and requiring many skills and responsive, trusting relationships. Relational care is dynamic, iterative, and heterogeneous. Each interaction is unique and adaptive to the patient and the context. One cannot prescribe fixed rules for compassionate care, although certain rules of etiquette can help to personalize care, such as informing patients of one's role and name. ${ }^{73,74}$ Compassion is about connection and reciprocity, flowing cyclically inward and outward. The organization as a living human system, like any ecosystem in nature, provides a coherent metaphor, which can accommodate human motivation and emotions. ${ }^{75}$ Adopting this view allows for emergent design, such that small groups or teams can be self-organizing and solve problems as and when they arise. ${ }^{76}$ Organizations with rapid changes, uncertainty, and complex problems require flexible responsive healthcare organizations with leaders who can inspire others to participate in teamwork and patient focused goals.

\section{Culture and leadership for compassionate care}

Culture can be defined as the shared values, assumptions, and beliefs within occupational groups or organizations. These are translated into norms of practice reinforced by rituals, ceremonies, and shared narratives. ${ }^{77}$

Health care organizations need to nurture cultures that ensure the delivery of high-quality, safe, and compassionate health care. In a large multimethod study, the best performing organizations were those that gave priority to a vision and strategy for high-quality compassionate care. Leadership is seen as the most influential factor in shaping organizational culture. But one could also argue that culture influences the emergence of different kinds of leadership and they are in a reciprocal, even synergistic, relationship. Hospitals' structure and culture may be major determinants of leadership styles. Evidence suggests that transformational leadership, and by inference, compassionate leadership, cannot thrive in organizations (including many hospitals) with "negative organizational receptivity". These focus on efficiency and use task systems dominated by technical cores, machine bureaucracy, and market or bureaucratic governance. ${ }^{78}$

In contrast, caring cultures ensure that staff members are engaged by being valued, respected, and supported. Engaged staff are more likely to provide compassionate safer care and higher patient satisfaction. ${ }^{79}$

But cultural diversity and complexity can exist within a health service with multiple, often competing, subcultures. This "cultural mosaic", combined with policy imperatives from politicians, can make it challenging to create unified visions for compassionate patient-centered care. ${ }^{80}$

Kanov et al described three collective compassion subprocesses with examples that reflect the culture of the organization: collective noticing, feeling, and responding. ${ }^{81}$ To sustain cultures of compassion, whereby patients are ensured high-quality compassionate care, West et al ${ }^{82}$ identified six key cultural elements: inspiring visions, operationalized at all levels; clear aligned objectives for individuals, teams, and departments; high level of staff engagement; supportive and enabling people management; learning, innovation, and quality improvement embedded in everyone's practice; and effective teamwork.

The competing values framework provides a useful diagnostic tool for evaluating organizational culture. ${ }^{83}$ For adaptive organizations with compassionate leadership and compassion permeating all domains, the weighting should be toward a dominance of the value drivers of clan (collaboration) with some ad-hocracy (creativity and flexibility). Hierarchy (control and stability) should be applied only when strictly necessary, such as in crises or when procedures require a uniform and routinized approach. It is arguable whether market values (competition and profit) apply at all in an NHS, as efficiency and "customer" focus can be accommodated within clan and ad-hocracy. ${ }^{84}$ Market values create the self-focused competitive mentality associated with compassion deficit. This is borne out by research which found that clan cultures in hospitals were associated with higher staff morale and fewer patient complaints. The opposite was true of market cultures. Hierarchical cultures were associated with poor outcomes and a climate of fear. ${ }^{85,86}$ Disappointingly, in response to evidence of organizational 
failures, the emphasis has been yet more bureaucracy and regulation, and "doing more of the wrong thing righter" ${ }^{87}$ In the UK, the market model of health care has not been relinquished; indeed, it has been promoted. General practitioners in the UK working with primary care professionals were able to function as relatively autonomous self-organizing teams, but imposed target-driven bureaucracy and industrialization have changed this and led to fragmentation and loss of personal holistic care. ${ }^{88}$

In practice, a cultural shift toward adaptive, collaborative, and creative health care organizations means that much of the daily decision-making can be left to small self-organizing multidisciplinary teams. The management is primarily coaching and supportive. Professional barriers are overcome, and clinicians engage more with patients and work with them to bring about change and innovation, treating them as coproducers of health, not passive recipients of care. ${ }^{89}$ We have evidence that management-light self-organizing teams working with patients and clients within large organizations can work; for example, Buurtzorg has revolutionized community nursing in the Netherlands. ${ }^{90}$ Other shining examples provide hope for change. ${ }^{91}$

\section{Implications for compassionate leadership development}

Leadership development is underpinned by human adult development and is a dynamic process built on a foundation of trust and respect." Much of the research into "leadership development" is actually about leader development. Traditional leader-centric development programs by external providers in remote locations with tenuous links to organizational outcomes continue to dominate. ${ }^{93}$ The evidence that this leads to improved leadership or compassionate leadership is weak. ${ }^{83}$ The implications of shared or collective leadership are clear: education and training in leadership skills also needs to be collective, ie, for all those working in health care organizations, including those who do not consider themselves as leaders, in order to create a collective leadership culture of compassion and collaboration. Preferably, the training should be in the form of multidisciplinary "in-house" team coaching and training. People will need to learn to be adept at managing across boundaries and disciplines. Managers will need to be trained in coaching skills to support staff. Turnbull advocates for programs that promote shared, "post heroic", collaborative, distributed leadership, beginning with the issues patients face and learning in the context of application.

From the empirical evidence, it is clear that we need to nurture and cultivate facilitators, team builders, mentors, and coaches (clan) as well as individuals in large numbers who are creative, transformative, and adaptive (ad-hocracy). Hard-driving competitive leadership (market), characteristics of pacemakers, and bureaucratic and controlling leaders (hierarchy) need to be present in very small doses. Yet evidence shows that pacemakers make up to $70 \%$ of the NHS senior leadership. ${ }^{94}$ This needs to be urgently addressed.

Frost et al propose three lenses that serve as a blueprint for the development of compassion in organizations:

1. Compassion as interpersonal work, which requires effortful skill and competence, involves cognitive and emotional energy, and recognizes that small acts of compassion can have large consequences.

2. Compassion as narrative: reflecting, and making sense of the hidden pain of the organization reveals shared experiences, values, and beliefs; allows for multiple voices; and restores connection, shared identity, and common purpose.

3. Compassion as organizing with collective noticing, feeling, and responding to suffering, reliance on feedback loops, and interdependent observations. ${ }^{95}$

There will still be a need for some individualized senior leadership development, but the focus should be on developing servant and adaptive leadership attributes and practices. Senior leaders will require the capacity to establish a collective vision to support the greater good, make connections and work across boundaries, tolerate uncertainty, collate multiple perspectives, and ensure that leadership is distributed. They will need to embody and model compassionate attitudes and behaviors and receive the support and training to develop and maintain self-compassion and emotional resilience.

\section{Resilience building: methods and processes}

Clinicians are exposed to high levels of negative emotions in stressful environments and need to be proficient in emotional regulation skills and adaptive strategies to cope. Training and education will no doubt help, but the environment has to be conducive to compassionate care. No amount of "resilience" will withstand unsupportive or toxic organizational cultures, particularly if the heroes who speak up are silenced or forced to leave. Nor can we expect compassionate leadership to be sustainable in the context of inadequate resources (including staffing levels) and insufficient support.

A variety of validated methods can be used to develop shared/collective compassionate leadership. Evidence shows that "happy staff make happy patients", and investing in staff well-being and support is a clear leadership priority. 
Schwartz Center Rounds ${ }^{\circledR}$ allow for staff to come together and discuss difficult emotional and social issues in caring for patients. These show evidence of improving staff well-being and morale. ${ }^{96}$ Appreciative inquiry builds strengths and creates a vocabulary of hope, inspiring and motivating people to change. It gives a core perception of capability and activates community building with extensive use of storytelling. It engages people in learning, planning, and innovation and focuses on best practices. Several medical schools and health care institutions report positive outcomes. ${ }^{97}$ Appreciative inquiry and appreciative storytelling combined with mindfulness training has been shown to benefit doctors' well-being, enhance empathy, decrease burnout, and increase patient satisfaction. ${ }^{98,99}$ Positive deviance - a variant of appreciative inquiry - is also a promising method, focusing on those that buck a negative trend and achieve good results. Mindfulness meditation and compassionate mind training can increase responsiveness to suffering and psychological flexibility, enhance patient-centered valuedirected care, and increase self-compassion and emotional resilience. ${ }^{100-102}$ Many mindfulness training programs have been developed in health care settings. Coaching is also widespread and popular and can be tailored for compassionate leadership. ${ }^{103}$ Empathy (compassion) training programs have also been successful. ${ }^{104}$

\section{Conclusion}

In conclusion, to develop compassionate leadership in health care, we need a paradigm shift from an engineering hierarchical model of organizations with trait-based, top-down individualistic models of leadership toward a model of the organization as a complex living system and leadership as adaptive, shared, and distributed. This is in keeping with modern organizational and scientific theories and a great deal of empirical evidence. It is also philosophically coherent. The inevitable anxiety related to caring for the sick and dying needs to be recognized and contained in an adaptive and healthy way. Educational and development strategies for leadership need to reflect the earlier discussion and be evidence-based, collective, and ideally "home-based". Development for compassionate leadership means fostering leaders, who embody and enact the qualities of servant leadership: altruism, integrity, humility, and wisdom combined with an appreciation and empowerment of others. Developing a compassionate and person-centered organization requires senior leaders to clearly articulate the core values and vision of the health service and to ensure that they resonate in all the self-organizing groups within the system. Leadership should support, engage, and enable staff and patients in a meaningful way.

Yet more regulation and bureaucracy will stifle innovation and impede the flow of compassion. To quote Don Berwick: "Make sure pride and joy in work, not fear, infuse the NHS". 5 This statement can be applied to all health care organizations, large and small, whose members endeavor to alleviate suffering and promote the flourishing of others.

\section{Disclosure}

The author reports no conflicts of interest in this work.

\section{References}

1. Francis R. Independent Inquiry into Care Provided by Mid Staffordshire NHS Foundation Trust January 2005-March 2009. London: Stationery Office; 2010.

2. Francis R. Report of the Mid Staffordshire NHS Foundation Trust Public Inquiry. London: The Stationery Office; 2013. [HC-898-1-111].

3. Abraham A. Health Service Ombudsman. Care and Compassion? Report of the Health Service Ombudsman on Ten Investigations into NHS Care of Older People, HC 778. London: The Stationery Office; 2011.

4. Department of Health. Developing the Culture of Compassionate Care: Creating a New Vision and Strategy for Nurses, Midwives and Caregivers. London: HSMC; 2012.

5. Berwick D. A Promise to Learn - A Commitment to Act: Improving the Safety of Patients in England. London: National Advisory Group on the Safety of Patients in England; 2013.

6. Lown BA, Rosen J, Marttila J. An agenda for improving compassionate care: a survey shows about half of patients say such care is missing. Health Aff. 2011;30(9):1772-1778

7. Boorman Review. NHS Health and Well-Being Review: Final Report. London: Department of Health; 2009.

8. Lucian Leape Institute and National Patient Safety Foundation. Through the Eyes of the Workforce: Creating Joy, Meaning in Work and Safer Healthcare. Boston: National Patient Safety Foundation; 2013.

9. Paparella G. Understanding StaffWellbeing, its Impact on Patient Experience and Healthcare Quality. Oxford: Picker Institute Europe. Available from: http://www.pickereurope.org. Accessed July 30, 2015.

10. Dixon-Woods M, Baker R, Charles K, et al. Culture and behaviour in the English National Health Service: overview of lessons from a large multimethod study. BMJ Qual Saf. 2013;23:1-10.

11. Frost PJ, Dutton JA, Worline MC, Wilson A. Narratives of compassion in organizations. In: Fineman S, editor. Emotion in Organizations. 2nd ed. London: Sage; 2000:25

12. Sweeney K, Toy L, Cornwell J. A patient's journey: mesothelioma. BMJ. 2009;339:512.

13. Frank AW. The Renewal of Generosity: Illness, Medicine and How to Live. Chicago: University of Chicago; 2004.

14. Montague E, Chen P, Xu J, Chewning BA, Barrett B. Nonverbal interpersonal interactions in clinical encounters and patient perceptions of empathy. J Particip Med. 2013;5:e33.

15. Decety J, Fotopoulou A. Why empathy has a beneficial impact on others in medicine: unifying theories. Front Behav Neurosci. 2015;8:1-11.

16. Youngson R. Time to Care. Raglan: Rebelheart; 2012.

17. Mannion R. Enabling compassionate healthcare: perils, prospects and perspectives. Int J Health Policy Manag. 2014;2(x):1-3.

18. Goetz JL, Keltner D, Simon-Thomas E. Compassion: an evolutionary analysis and empirical review. Psychol Bull. 2010;136(3):351-374.

19. Gilbert P. The Compassionate Mind. London: Constable Robinson; 2009.

20. Nussbaum MC. Compassion: the basic social emotion. Soc Philos Policy. 1996;13:27-58. 
21. Chochinov J. Dignity and the essence of medicine: the A, B, and C and D of dignity conserving care. BMJ. 2007;335(184-187):184.

22. de Zulueta PC. Suffering, compassion and 'doing good medical ethics'. J Med Ethics. 2015;41:87-90.

23. Lazarus RS, Folkman S. Stress, Appraisal and Coping. New York: Springer; 1984.

24. Eisenberg N. Emotion, regulation and moral development. Anпu Rev Psychol. 2000;51:665-697.

25. Halifax J. The precious necessity of compassion. J Pain Symptom Manage. 2011;41(1):146-153.

26. Batson CD, Early S, Salvarini G. Perspective taking: imagining how another feels versus imagining how you would feel. Pers Soc Psychol Bull. 1997;23(7):751-758.

27. Cassell EJ. The Nature of Suffering and the Goals of Medicine. 2nd ed. New York: Oxford University Press; 2004.

28. Gilbert P, Choden. Mindful Compassion: How the Science of Compassion Can Help You Understand Your Emotions, Live in the Present, and Connect Deeply with Others. Oakland: New Harbinger Publications; 2014.

29. Bandura A. Self-Efficacy: The Exercise of Control. New York: W.H. Freeman; 1997.

30. Lamothe M, Boujut E, Zenasni F, Sultan S. To be or not to be empathic: the combined role of empathic concern and perspective taking in understanding burnout in general practice. BMC Family Practice. 2014;15:15.

31. Gilbert P. Social mentalities: a biopsychosocial and evolutionary reflection on social relationships. In: Baldwin M, editor. Interpersonal Cognition. New York: Guildford Press; 2005.

32. Ballatt J, Campling P. Intelligent Kindness: Reforming the Culture of Healthcare. London: The Royal College of Psychiatrists Publications; 2011.

33. de Zulueta P. Compassion in 21 st century medicine: is it sustainable? Clin Ethics. 2013;8(4):119-128.

34. Delbanco T, Bell SK. Guilty, afraid and alone - struggling with medical error. N Engl J Med. 2007;357:1682-1683.

35. Boyatzis RE, Rochford K, Jack AI. Antagonistic neural networks underlying differentiated leadership roles. Front Hum Neurosci. 2014;8:114.

36. Catarino F, Gilbert P, McKewan K, Baiao R. Compassion motivations: distinguishing submissive compassion from genuine compassion and its association with shame, submissive behaviour, depression, anxiety and stress. J Soc Clin Psychol. 2014;33(5):399-412.

37. Hochschild A. The Managed Heart: Commercialization of Human Feelings. Oakland: University of California Press; 1983.

38. Fernando AT III, Consedine N. Development and initial psychometric properties of the barriers to physician compassion. Postgrad Med J 2014;90:388-395.

39. Firth-Cozens J, Cornwell J. Enabling Compassionate Care in Acute Hospital Settings. London: King's Fund; 2009.

40. Maben J, Latter S, Clark M. The theory-practice gap: impact of professional bureaucratic work conflict on newly-qualified nurses. $J A d v$ Nurs. 2006;55(4):465-477.

41. Molinsky A, Grant AM, Margolis JD. The bedside manner of homo economicus: how and why priming an economic schema reduces compassion. Organ Behav Hum Decis Process. 2012;119:27-37.

42. Batson CD, Cochran PJ, Biederman MF, Blosser JL, Ryan MJ, Vogt B. Failure to help when in a hurry: callousness or conflict? Pers Soc Psychol Bull. 1978;4(1):97-101.

43. Ryan RM, Deci EL. Self-determination theory and facilitation of intrinsic motivation, social development and well-being. Am Psychol. 2000;55(1):68-78.

44. Neff KD, Kirkpatrick KL, Rude SS. Self-compassion and adaptive psychological functioning. J Res Pers. 2007;41:139-154.

45. Batts A, Leary MR. Self-compassion, stress and coping. Soc Personal Psychol Compass. 2010;4(2):107-118.

46. Francis R. Freedom to Speak Up. An Independent Review into Creating an Open and Honest Reporting Culture in the NHS; 2015. Available from: http://webarchive.nationalarchives.gov.uk/20150218150343/https:// freedomtospeakup.org.uk/wp-content/uploads/2014/07/F2SU_web.pdf.
47. Rost JC. Leadership in the 21st Century. New York: Praeger; 1991.

48. Drath WH, McCauley CD, Palus CJ, Van Velsor E, O'Connor PMG, McGuire JB. Direction, alignment, commitment: toward a more integrative ontology of leadership. Leadersh Q. 2008;19:635-653.

49. Plsek PE, Wilson T. Complexity, leadership and management in healthcare organisations. BMJ. 2001;323:746-749.

50. Uhl-Bien M. Relational leadership theory: exploring the social processes of leadership and organizing. Leadersh Q. 2006;17:654-676.

51. Suchman AL. How we think about organizations: a complexity perspective. In: Suchman AL, Sluyter DJ, Williamson PR, editors. Leading Change in Healthcare: Transforming Organizations Using Complexity, Positive Psychology and Relationship-Centered Care. London: Radcliffe Publishing; 2011:11-24

52. Alimo-Metcalfe B, Alban-Metcalfe J. Leadership: time for a new direction? Leadership. 2005;1(1):51-71.

53. King's Fund. The Future of Leadership and Management in the NHS. Report from the King's Fund Commission on Leadership and Management in the NHS. No More Heroes. London: King's Fund; 2011.

54. West M, Lyubovnikova J, Eckert R, Denis J-L. Collective leadership for cultures of high quality health care. J Organ Eff People Perform. 2014;1(3):240-260.

55. Nye JS. The Powers to Lead - Hard, Soft and Smart. New York: Oxford University Press; 2008.

56. Avolio BJ, Gardner WL. Authentic leadership development: getting to the root of positive forms of leadership. Leadersh Q. 2005; 16(3):315-338.

57. Bass BM. Two decades of research and development in transformational leadership. Eur J Work Organ Psychol. 1999;8(1):9-32.

58. Tourish D. The Dark Side of Transformational Leadership: A Critical Perspective. Hove, UK: Routledge; 2013.

59. Boyatzis R, McKee A. Resonant Leadership: Renewing Yourself and Connecting with Others Through Mindfulness, Hope and Compassion. Boston: Harvard Business School Press; 2005.

60. George JM. Emotions and leadership: the role of emotional intelligence. Hum Relat. 2000;53(8):1027-1055.

61. Akerjordet K, Severinsson E. Emotional intelligence: a review of the literature with specific focus on empirical and epistemological perspectives. J Clin Nurs. 2007;16(8):1405-1413.

62. Skinner C, Spurgeon P. Valuing empathy and emotional intelligence in health leadership: a study of empathy, leadership behavior and outcome effectiveness. Health Serv Manage Res. 2005;18:1-12.

63. Autry JA. The Servant Leader: How to Build a Creative Team, Develop Great Morale, and Improve Bottom-Line Performance. New York: Three Rivers Press; 2001.

64. Stone AG, Russell RF, Patterson K. Transformational Versus Servant Leadership: A Difference in Leader Focus. London: School of Leadership Studies, Regent University; 2003.

65. Russell RS, Stone AG. A review of servant leadership attributes: developing a practical model. Leadersh Organ Dev J. 2002;23(3): $145-157,154$.

66. Grint K. Wicked problems and clumsy solutions: the role of leadership. Clin Lead. 2008;1(11):1757-3424.

67. Schein EH. Humble Inquiry: The Gentle Art of Asking Instead of Telling. Oakland: Berrett-Koehler; 2013.

68. Heifetz R, Laurie DL. The work of leadership. Harv Bus Rev. 1997; 75(1):124-134.

69. Taylor FW. The Principles of Scientific Management. New York: Harper and Brothers; 1911.

70. Christoff K. Dehumanization in organizational settings: some scientific and ethical considerations. Front Hum Neurosci. 2014;8:1-3.

71. Johnson M, Lakoff G. Metaphors We Live By. Chicago: Chicago University Press; 1980.

72. Morgan G. Images of Organization. 4th ed. Thousand Oaks: Sage; 2006.

73. Kahn MW. Etiquette based medicine. $N$ Engl J Med. 2008;358: 19-20. 
74. Granger K. Healthcare staff must properly introduce themselves to patients. BMJ. 2013;347:f5833.

75. Lewis S, Passmore J, Cantore S. Appreciative Inquiry for Change Management: Using AI to Facilitate Organizational Development. London: Kogan Page; 2008.

76. Laloux F. Reinventing Organizations: A Guide to Creating Organizations Inspired by the Next Stage of Human Consciousness. Brussels: Nelson Parker; 2014.

77. Schein EH. Organizational Culture and Leadership. 4th ed. New York: Jossey-Bass; 2010.

78. Stordeur S, Vanderburghe C, D'Hoore W. Leadership styles across hierarchical levels in nursing departments. Nurs Res. 2000;49(1):37-43.

79. The King's Fund. Leadership and Engagement for Improvement in the NHS: Together We Can. London: King' Fund; 2012.

80. Davies HTO, Mannion R. Will prescriptions for cultural change improve the NHS? BMJ. 2013;346:f31305.

81. Kanov JM, Maitlis S, Worline MC, Dutton JE, Frost PJ, Lilius JM. Compassion in organizational life. Am Behav Sci. 2004;47(6): 808-827.

82. West MA, Armit K, Loewenthal L, Eckert R, West T, Lee A. Leadership and Leadership Development in Health Care: The Evidence Base. London: The Faculty of Medical Leadership and Management, The King's Fund; Brussels: The Centre for Creative Leadership; 2015.

83. Quinn RE, Rohrbaugh J. A spatial model of effectiveness criteria: towards a competing values approach to organizational analysis. Manage Sci. 1983;29:363-377.

84. Flynn M, Mercer D. Is compassion possible in a market-led NHS? Nurs Times. 2013;109(7):12-14.

85. Meterko M, Mohr DC, Young GJ. Teamwork culture and patient satisfaction in hospitals. Med Care. 2004;42:492-498.

86. Davies HTO, Mannion R, Jacogs R, Powell AE, Marshall MN. Exploring relationship between senior management team culture and hospital performance. Med Care Res Rev. 2007;64(1):46-65.

87. Seddon J. Systems Thinking in the Public Sector. Axminster: Triarchy Press; 2008.

88. Iliffe S. From General Practice to Primary Care: The Industrialization of Family Medicine. Oxford: Oxford University Press; 2008.

89. Coulter A. Leadership for Patient Engagement. London: King's Fund; 2012.

90. Buurtzorg. Available from: http://www.buurtzorgnederland.com/. Accessed September 8, 2015.
91. Hannah M. Humanizing Healthcare: Patterns of Hope for Systems Under Strain. Axminster: Triarchy Press; 2014.

92. Day DV. Leadership development: a review in context. Leadersh $Q$. 2000;11:581-613.

93. Turnball James K. Leadership in Context: Lessons from New Leadership Theory and Current Leadership Development Practice. London: The King's Fund; 2011.

94. Ham C. Reforming the NHS from Within. London: King's Fund; 2014.

95. Frost PJ, Dutton JE, Maitlis S, Lilsius JM, Kanov JM, Worline MC. Seeing organizations differently: three lenses on compassion. In: Clegg SR, Hardy C, Lawrence TB, Nord WR, editors. The Sage Handbook of Organizational Studies. 2nd ed. London: Sage; 2006:843-865.

96. Lown BA, Manning CF. Schwartz center rounds: evaluation of an interdisciplinary approach to enhancing patient-centered communication, teamwork and provider support. Acad Med. 2010;85:1073-1081.

97. Suchman A, Williamson PR, Litzelman DK, et al; Relationship-Centered Care Initiative Discovery Team. Towards an informal curriculum that teaches professionalism. Transforming the social environment of a medical school. J Gen Intern Med. 2004;19:501-504.

98. Krasner MS, Epstein RM, Beckman H, et al. Association of an educational program in mindful communication with burnout, empathy and attitudes among primary care physicians. JAMA. 2009;302: 1284-1293.

99. Raab K. Mindfulness, self compassion and empathy among health care professionals: a review of the literature. J Health Care Chaplain. 2014;20:95-108.

100. Condon P, Desbordes G, Miller WB, DeSteno D. Meditation increases compassionate responses to suffering. Psychol Sci. 2013; XX(X):1-3.

101. Atkins NJ, Parker SK. Understanding individual compassion in organizations: the role of appraisals and psychological flexibility. Acad Manag Rev. 2012;37(4):524-526.

102. Seppala EM, Hutcherson CA, Nguyen DTH, Doty JR, Gross JJ. Loving-kindness meditation: a tool to improve healthcare provider compassion, resilience and patient care. J Compassionate Health Care. 2014;1:5.

103. McKee A, Johnston F, Massimilian R. Mindfulness, hope and compassion: a leader's road map to renewal. Ivey Bus J. 2006;70(5):1-5.

104. Riess H, Kelley JM, Bailey RW, Dunn EJ, Phillips M. Empathy training for resident physicians: a randomised controlled trial of a neuroscienceinformed curriculum. J Gen Intern Med. 2012;27:1280-1286.
Journal of Healthcare Leadership

\section{Publish your work in this journal}

The Journal of Healthcare Leadership is an international, peer-reviewed, open access journal focusing on leadership for the health profession. The journal is committed to the rapid publication of research focusing on but not limited to: Healthcare policy and law; Theoretical and practical aspects healthcare delivery; Interactions between healthcare and society and evidence-based practices;

\section{Dovepress}

Interdisciplinary decision-making; Philosophical and ethical issues; Hazard management; Research and opinion for health leadership; Leadership assessment. The manuscript management system is completely online and includes a very quick and fair peer-review system. Visit http://www.dovepress.com/ testimonials.php to read real quotes from published authors. 